the couple-of-miles range - which these days isn't that deep," says Cameron. "What is the future of deep submergence research?"

That future once looked boundless. On 17 February 1977, Alvin skimmed along the ocean bottom about 400 kilometres northeast of the Galapagos Islands. Days before, sensors towed by a ship had identified a spike in water temperatures near the sea floor. Alvin explored the region and brought researchers face to face, for the first time, with hydrothermal vents, fissures in the sea floor that spew streams of warm, shimmering brine into the near-freezing water. In what was supposed to be a barren desert at the ocean bottom - far from the reaches of lifepowering sunlight - Alvin revealed oases of clams, crabs, shrimp and alien-like white tube worms crowned with crimson tops.

Two years after the Galapagos dives, an Alvin expedition witnessed a more violent scene: jets of black fluids, superheated to $400^{\circ} \mathrm{C}$, shooting out of gigantic chimneys of rock, which were dubbed black smokers. Later, in the geologically quieter Gulf of Mexico, Alvin found vents that were releasing cooler methane-rich fluids. These 'cold seeps' also support communities of animals, including slow-growing tube worms thought to be hundreds of years old - some of the most ancient creatures alive on the planet. The discovery of such ecosystems, powered by microbes that harness chemical energy from vent waters, raised questions about where life originated on Earth and where it may reside on other worlds.

Alvin's string of accomplishments silenced early critics - some of the top geoscientists of the 1960s and 1970s - who initially regarded the submersible as little more than a toy. And ever since, the vehicle has been in high demand, trekking to the sea floor 100-150 times a year. Although some countries can dive more deeply, Alvin "is the most reliable submersible there is", says Susan Humphris, a geochemist at WHOI and principal investigator of the Alvin overhaul. "We need a workhorse at the bottom of the ocean. That's what Alvin has been and that's what Alvin will continue to be."

\section{AT THE HELM}

Cindy Van Dover knows the submersible better than any other scientist. Now the director of the Duke University Marine Laboratory in Beaufort, North Carolina, Van Dover spent nearly three years training and working as an Alvin pilot after getting her doctorate at Woods Hole. She is the only researcher, and the only woman, to have piloted the craft, choosing to detour from a conventional research career because the job offered opportunities that few researchers can get. "I wanted to do a lot of dives," she says. "It was about wanting to see the environment that I was studying."

In 1991, when Van Dover gave up her pilot's seat and went back to being an occasional passenger in Alvin, one of the things she missed most was the view. The old sphere, built in 1973, had three 13-centimetre-wide viewports, one on each side for passengers and one at the front for the pilot. Through those saucer-sized side ports, Van Dover says, "sometimes it was a great view but often it wasn't, so you'd end up watching a video of what the pilot was doing". The new sphere retains the side windows but has three 18-centimetre-wide ones at the front, giving researchers a field of view that overlaps with the pilot's (see 'Voyager to the bottom of the sea').

The space inside the sphere has also grown, which should make for less-painful rides. With an internal diameter of less than 2 metres, the old sphere had no room for seats; scientists had to huddle on the floor, and lean awkwardly against the sloped walls. After a 2-hour descent to the bottom, limbs would stiffen up. "You switch your position because your legs are so uncomfortable and you rock the whole submersible," says Chris German, a marine geochemist at WHOI and chief scientist for the US National Deep Submergence Facility in Woods Hole, which coordinates the use of Alvin. "That can compromise taking the samples."

The new sphere has 18\% more interior space and will have ergonomically designed seats. And while sampling or exploring, researchers will be able to take advantage of brighter lights and improved camera systems.
Scientists are keen to use the tools to explore the geology and biology of the mid-ocean ridges, the 60,000-kilometre-long chain of volcanic fissures that forge new ocean crust. So far, oceanographers have surveyed only a tiny fraction of the ridge system. The ridges and their flanks hide a subsurface plumbing network of fissures and pores so extensive that it circulates a volume of water equal to the entire ocean about every million years or so, altering the chemistry of the seas. Future dives will also target the communities of microbes living beneath the sea floor, which has been estimated to constitute as much as one-third of the planet's biomass. And marine scientists want to study the vast abyssal

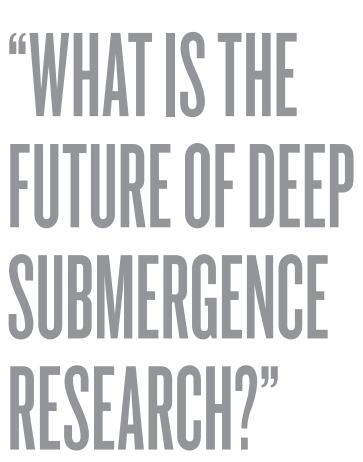
plains, which cover more than half of Earth's surface and are poorly explored; most of the species that researchers pull up in samples from abyssal sites are new to science.

But some places that scientists want to visit lie deeper than 4,500 metres and so will remain off-limits to Alvin for now. The National Science Foundation, which is funding most of the Alvin redesign, could not afford to build a 6,500-metre-class sub all at once. In particular, such deep dives require more energy and it would be prohibitively expensive to build a submersible that uses current battery technology to dive frequently and to greater depths.

Rich Lutz, an oceanographer at Rutgers University in New Brunswick, New Jersey, who has racked up more Alvin dives than perhaps any scientist, was surprised to learn that the current overhaul won't add to the sub's depth range. "I certainly would have assumed that one of those improvements would be the capability of going down to 6,500 metres," he says.

\section{BOTTOM DWELLER}

Yet depth isn't everything. Despite the excitement over record-breaking dives by China's Jiaolong (7,020 metres) and Cameron's Deepsea Challenger (11,000 metres), researchers don't go deep very often. Fewer than $10 \%$ of the dives by the French and Japanese submersibles approach their limits. Vincent Rigaud, manager of the underwater systems department at the French Research Institute for Exploration of the Sea in La Seyne-sur-Mer, says that research is increasingly focusing on shallower depths. "The science today is linked to [minerals] exploitation or areas where there is an impact from man's activities or man's interests," he says.

Some US researchers are more upset about other limitations of the new Alvin. "It's a superb tool for what it does but it could have been a hell of a lot better," says Bruce Robison, a marine ecologist at the Monterey Bay Aquarium Research Institute in Moss Landing, California. In 2004, Robison was a member of a committee of the National Research Council that assessed the future needs of deep submergence science. One of his biggest wishes was for a human-occupied vehicle (HOV) that could adjust its buoyancy to stop at any depth, allowing researchers to work well above the ocean floor. Most of the biological and chemical process in the ocean take place in the water column, not on the sea floor, Robison says. Yet neither the old Alvin nor the rebuilt sub can adjust its buoyancy enough to linger above the sea floor without draining its batteries. So nearly all trips go straight to the bottom.

Along with concerns over Alvin's limitations, US researchers also lament the loss of several scientific submersibles. Funding woes forced Florida International University's Harbor Branch Oceanographic Institute in Fort Pierce to retire its two submersibles, the Johnson Sea Links, last year. And the National Oceanic and Atmospheric Administration plans to stop funding the National Undersea Research Program, which supports two Pisces submersibles located in Hawaii. The two HOVs are known for their work exploring seamounts in the Pacific Ocean, including the newest Hawaiian volcano. Robison bemoans the loss of 


\section{VOYAGER TO THE BOTTOM OF THE SEA}

A US\$40-million upgrade to Alvin will lead to noticeable improvements for researchers, but the submersible will have the same depth limit, 4,500 metres, as the previous one. Only five nations - and entrepreneur

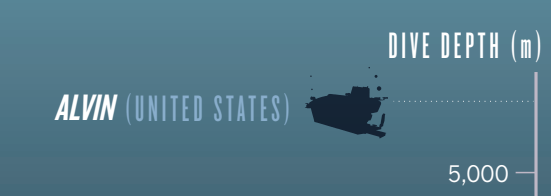

$\begin{array}{ll}\text { Thrusters } & \text { Cameras }\end{array}$ Alvin has been outfitted to enhance manoeuvrability.

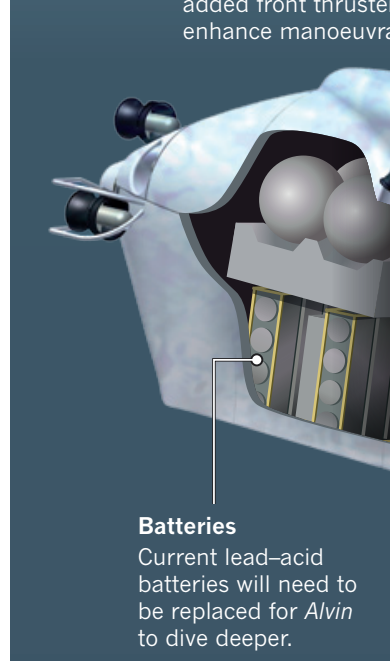

$$
\text { ility. }
$$

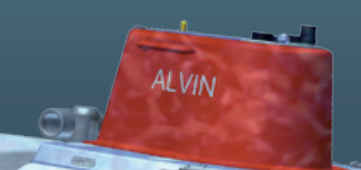
with brighter lights and high-definition cameras.

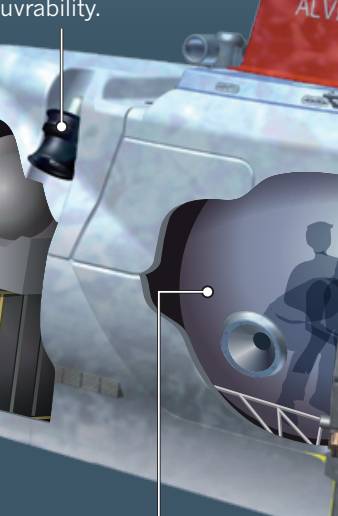

Personnel sphere An $18 \%$ increase in its size means more
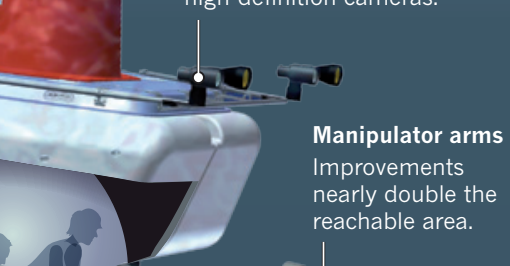
reachable area.
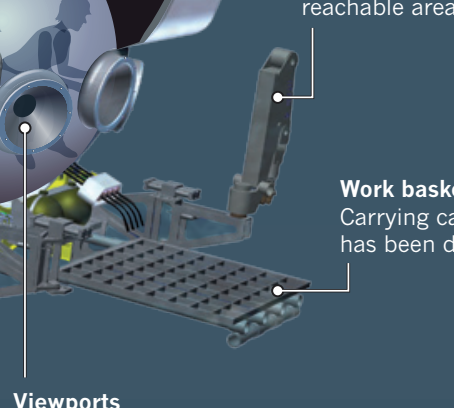
nearly double the

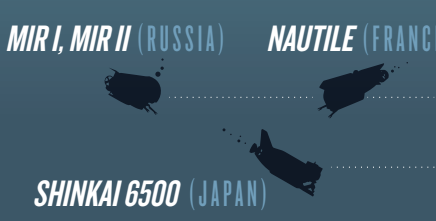

6,000

SHINKAI 6500

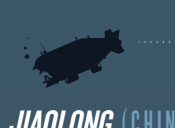

7.000 JAOLONG (CHINA)

all the other US scientific submersibles. "As good as Alvin is," he says "that isn't enough."

Veteran explorer Robert Ballard is not shedding any tears over the HOVs. "I consider that a dead paradigm," says the marine geologist who discovered the Titanic and co-led the cruise that discovered the first hydrothermal vents; he used Alvin to explore them both. He now relies on autonomous underwater vehicles (AUVs) and remotely operated vehicles (ROVs), which can be controlled by researchers on a ship or from halfway across the world. "AUVs augmented with ROVs is where I see the future. I don't need any people in them."

Alvin is limited to 4-5 hours of work at depth, whereas ROVs can spend days on the bottom and some AUVs can explore for months. And unmanned vehicles don't require such large support ships and crews as HOVs, which can trim the cost of a mission substantially. Thanks to their data links, ROVs also enable essentially unlimited numbers of researchers around the world to take part in missions.

The ROV Jason 2 has become a favourite tool of US marine geologists, who love its flexibility in exploring and collecting samples down to 6,500 metres. But its heavy steel cable, which supplies power and transmits data, prevents the ROV from diving deeper and complicates missions.

Just up the hill from where Alvin is taking shape at Woods Hole, researchers are working on an experimental vehicle that will sever that troublesome umbilical cord while retaining the advantages of an ROV. Canary yellow and the size of a delivery van, Nereus made headlines in 2009 by reaching the bottom of Challenger Deep in the South Pacific - at 11,000 metres, the lowest spot on Earth. Nereus can operate either autonomously or connected to a surface ship through a fibre-optic cable.

But the tether, just three times the thickness of a human hair, breaks easily. So the Woods Hole team is now working to cut the physical link with the surface. This month, off Guam, the crew will test a laser system on Nereus that sends the data

\section{ONATURE.COM} For an interview with filmmaker James Cameron visit: go.nature.com/uvjdyw to a receiver hanging down from a ship. Researchers will control Nereus using acoustic signals from the ship.

Despite the advantages of ROVs, most scientists say that there is no substitute for exploring the depths in person. "There is still a place for having a human brain and eyes at the bottom of the ocean," says Humphris. To those who say there is no need for HOVs, she says "It's a little bit like saying, 'Why would you go to the Grand Canyon rather than watching a movie about it?'”

Alvin is also one of the best recruiting tools in marine science. "It's what has brought the very best minds to the deep-sea oceanographic community", says Lutz. "You're able to tell them, 'You come work with us and we're going to take you a mile and a half down to the bottom of the sea in a submersible,' as opposed to saying, 'We're going to take you out on a ship and you're going to watch it on a television screen."

Private money could help to preserve some opportunities for deepsea science. Eric Schmidt, former chief executive of Google, purchased an 83-metre-long ship in 2010 that he retrofitted for oceanographic science. His Schmidt Ocean Institute will start research cruises with the vessel next year and will test existing ROVs with the aim of purchasing one in a couple of years and making it available for researchers.

And Cameron's dive aboard his one-person Deepsea Challenger fired up the imagination of researchers such as Lutz. "You look at it as a scientist and say, 'Shit! I'd go down in that thing"'

Cameron says that his sub is available for anyone willing to put up the money for further expeditions. "I'm more than happy to put in the sub and the technology. It's not doing any good sitting in my barn," he says.

In the meantime, the hopes of the US oceanographic community ride on Alvin, which currently rests in pieces at Woods Hole. Looking up at the gleaming passenger sphere, Strickrott takes a moment to picture the day his crew has completed all its work and Alvin is ready to dive once again. "When it gets rolled out here, it's spotless," he says. "It's a beautiful thing."

Richard Monastersky is a features editor for Nature. 